\title{
VIRUS OPHTHALMIA NEONATORUM
}

\author{
BY \\ ArNold SORSBy, ElizABeth E. Hoffa and \\ ELIZABETh N. Young
}

LONDON

INTRACELLULAR bodies in the cytoplasm of the conjunctival epithelium were demonstrated by Stargardt in 1909 in a case of bacteriologically negative ophthalmia neonatorum and in some cases of gonococcal ophthalmia. Confirmation of the first finding was soon given by Schmeichler (1909) and of the second by Heymann (1910). - These observations created difficult problems. In the first place, they raised the question as to whether ophthalmia neonatorum-which was generally regarded as gonococcal in origin and only occasionally due to other organisms-could occur in a non-organismal form, the exciting agent being the intracellular bodies observed. 'Secondly, the exact signifieance of these intracellular bodies required assessment. They had been described in 1907 by Halberstaedter and Prowazek in the conjunctival epithelium of trachoma and had been regarded by them as the causative agent of trachoma. Their occurrence in non-gonococcal and in gonococcal ophthalmia neonatorum was puzzling, and the suggestion emerged that these bodies were a non-specific reaction product to the agent of trachoma and of the gonococcus and possibly other organisms. One view (Herzog, 1910) attempted to unify gonorrhoea and trachoma, trachoma being regarded as gonococcal infection in which the organism had undergone changes adapting it to parasitism on the epithelial cell.

These three conflicting views: (1) that the extracellular bodies were the exciting cause of trachoma, $(2)$ that they were the reaction products of both the exciting agent of trachoma and of gonococcocal ophthalmia, and (3) that they were an involutionary form of the gonococcus, found no ready solution. Halberstaedter and Prowazek (1909) were unable to convince themselves of the unity of trachoma and gonorrhoea, for (in contrast to another observer (Jancke, 1910)) they found intracellular bodies in genital gonorrhoea, but also found inclusion bodies in three nongonococcal cases of ophthalmia neonatorum. 'This led them to believe that these bodies were independent of gonorrhoeal infection. Their view found support in Lindner's (1909) observation that inclusion bodies could be found in practically all cases of non-gonococcal ophthalmia neonatorum, and but rarely in the gonococcal form. Lindner's clear postulation of a non-organismal form of ophthalmia neonatorum produced by inclusion bodies was 
supported by the successful inoculation into monkeys of the vaginal secretion of a mother whose infant had shortly before suffered from inclusion blenorrhoea; in a baboon, the infected conjunctiva. showed numerous inclusion bodies. The genital origin of these infecting inclusion bodies was conclusively demonstrated by Halberstaedter and Prowazek (1910) by their finding of such bodies in the genital epithelium of a mother whose infant was suffering from inclusion blenorrhoea.

Lindner's postulation of a genital infection due to inclusion bodies and producing in the infant a. non-bacterial ophthalmia neonatorum and in animals an affection clinically and histologically similar to trachoma, inevitably raised the question of the relationship between inclusion blenorrhoea and trachoma. Lindner's own view is summarised by his name of Paratrachoma for inclusion blenorrhoea.

Following the brilliant and intensive pioneer investigations of around 1909-1911 but little progress was made until recent years, when the whole field of virus study has been enormously enriched. It is now possible to speak confidently of a neonatal form of inclusion conjunctivitis and to indicate some of its ressential features.

1. Incidence.-In a series of 261 cases of ophthalmia neonatorum (in 87 per cent. of which the causal factor could be determined) Thygeson (1936) had 23 cases (=8.8 per cent.) of inclusion blenorrhoea. This ranked third in order frequency, staphylococcus coming first with 51.7 per cent. and pneumococcus second with 13.0 per cent. (The gonococcus came lowest with one case ( 0.38 per cent.) - a tribute to the efficacy of silver nitrate prophylaxis at the Dept. of Obstetrics of the University of Iowa Hospital.) In relation to the number of births $(3,939)$ these 23 cases constituted an incidence of 0.8 per cent. In a second series of 7,209 births, at the Sloane Hospital for Women in New York there were 25 cases of inclusion conjunctivitis, making an incidence of 0.34 per hundred births (Thygeson and Stone, 1942). On statistics from the same hospital, Flack (1942) gives 94 cases of ophthalmia neonatorum in 6,289 births $(=1.49$ per cent.) ; inclusion blenorihoea was responsible for 32 instances, giving 34.0 , per cent. of all ophthalmia and an incidence of 0.51 per 100 births. James (1930) observed 4 cases in 2,446 deliveries, giving an incidence of 0.16 per hundred births, whilst Braley (1942) observed 16 cases in 495 deliveries, an incidence of 3.2 per cent. In Montreal, McKee (1942) found inclusion bodies in 42 out of 62 consecutive cases of ophthalmia neonatorum ; in 25 of these, epithelial cell inclusions alone were present, in 15 in combination with gonococci, and in single cases the associated organism was the pneumococcus and streptococcus respectively. 
2. Mode of Infection.-Subsequent to the demonstration by Halberstaedter and Prowazek (1910) of inclusion bodies in the genital epithelium of the mother of an infected baby, Lindner (1910) found inclusion bodies and free initial bodies in three instances of non-gonorrhoeal urethritis in men. Lindner, Fritsch and Hofstaetter (1910) and also Heymann (1910) succeeded in inducing a trachoma-like reaction in monkeys by inoculation with the infectious agent isolated from such urethritis, the eyes ' of affected infants and from the genital passages of their mothers. Thygeson (1934) found inclusion bodies in the vaginae of four mothers of affected infants, and in three of these the infectivity of the vaginal secretion was proved by the positive inoculation of the conjunctivae of the sphinx baboon. Thygeson and Mengert (1936) stressed the localization of inclusion bodies at the cervix, whilst Braley (1938) limited the zone to the transitional epithelium near the external os of the cervix where the columnar epithelium of the endocervix changes into the stratified squamous epithelium of the exocervix and vagina. In 1942 Thygeson and Stone found that cervical scrapings in 13 mothers of infected infants gave positive results 7 times microscopically and 10 times in inoculation experiments in the baboon. Seven of the 12 fathers who were interviewed told of having had a "urethritis of some sort" at some time of their lives and most admitted sexual promiscuity.

3. Incubation Period.-Thygeson studied in detail 11 cases in 1934, and supplemented these by 8 cases in 1936 (Thygeson and Mengert) and 38 in 1942 (Thygeson and Stone, 1942a). In a few cases the apparent onset of the affection was delayed beyond the tenth day, but generally occurred within $7 \cdot$ to 8 days; in no case had it come on before thè 5 th day. Three cases of accidental infection in obstetricians (Thygeson and Mengert, 1936; Thygeson and Stone, 1942) occurred 8 days, 7 days and (?) 7 days respectively:

4. Clinical $\backslash$ Features - Like most other forms of ophthalmia neonatorum inclusion blenorrhoea may vary considerably in severity. The untreated case is generally acute for 7 to 10 days, and may take three months or longer to subside. Thygeson speaks of " 3 to 14 months of chronicity with gradual diminution of the inflammation and secretion." Residual changes have not been observed. Thygeson (1936) holds that inclusion blenorrhoea can be distinguished clinically from other forms of ophthalmia neonatorum by the predominant involvement of the lower fornix and the presence of marked papillary hypertrophy (apart from the difference in incubation period). Elsewhere he does not consider that an accurate diagnosis can be made on the clinical signs alone (Thygeson and Mengert, 1936). Though the affection may be 
one-sided to begin with, the second .eye generally becomes involved. Pseudomembranes in the acute stage and scar-formation from the severity of the inflammation have been observed (Aust, 1933; Lumbroso, 1933 and 1934).

5. The Nature of the Infecting Agent.-Early attempts at filtering the virus were largely unsuccessful owing to the absorptive surfaces of the pores. The more recent filters of graded collodion membranes (grodocol filters) have enabled an estimate of the particle size as lying between 0.39 and 0.15 micron. Direct microscopic measurement of the elementary body shows it to be from 0.2 to 0.25 micron in diameter, whilst the initial body is 1 micron or more.

The virus is morphologically indistinguishable from the trachoma virus with its cycle of free elementary bodies entering the cytoplasm of an epithelial cell, swelling to an initial body, dividing to form initial bodies of large size and further subdividing to form smaller elementary bodies, which grow to occupy much of the cytoplasm and ultimately burst the cytoplasm to escape as free initial bodies in the surrounding secretion. Attempts to cultivate the initial bodies have so far failed. These aspects are fully discussed by Braley (1938, 1939 and 1940), Thygeson and Stone (1942), Thygeson (1943) and by van Rooyen and Rhodes (1940).

6. Response to Treatment.-In contrast to trachoma, in which opinions on the value of the sulphonamides are conflicting, there is general agreement that inclusion blenorrhoea responds quickly to this mode of treatment. (Allen, 1937; Thygeson, 1939 and 1941; Giddens and Howard, 1940 ; Lugossy, 1940 ; McKee, 1942 ; Braley, 1942.) According to Thygeson and Stone $(1942)^{b}$, sulphathiazole ointment locally is almost as satisfactory as oral administration.

7. Incidence of the Genito-Urinary Virus Infection Responsible for Inclusion Blenorrhoea.--In 131 non-pregnant women suffering from various gynaecological conditions other than gonococcal, the virus could be demonstrated five times either by microscopic examination or baboon inoculation, giving an incidence of 3.8 per cent. In 53 patients with gonococcal cervicitis (none of whom showed urethritis), inclusion bodies were seen 5 times, and baboon inoculation was successful in 3 of the 4 experiments carried'out. In 100 men with acute anterior urethritis, the virus of inclusion conjunctivitis was demonstrated 8 times by baboon inoculation; in 6 out of these 8 cases gonorrhoea was also present (Thygeson and Stone, $1942^{\mathrm{a}}$ ).

\section{Experience at White Oak Hospital}

During the period January 1, 1942, to December 31, 1943, 269 cases, of ophthalmia neonatorum have been treated at White Oak 
Hospital. A full account of these cases appears elsewhere (Sorsby and Hoffa, 1944); the present record concerns the 28 cases of inclusion blenorrhoea in this series. They constitute 10.4 per cent. of the total.

1. Diagnosis.-The diagnosis was made on the finding of inclu-, sion bodies in scrapings taken from the conjunctiva (Figs. 2, 3 . and 5).

Technique.-(1) Irrigation to wash away. all pus and muco-pus. (2) Instillation of gutt. adrenalin $1: 1,000$ to avoid excessive bleeding. (3) Scraping with a sharp chalazion spoon or scalpel to obtain a thin shaving of conjunctival epithelium, as free as possible from blood and discharge. (4) Transfer of two or three of such scrapings on to a slide. (5) Teasing of this material into as thin layers as possible. (6) Drying for 30 seconds over.a spirit lamp flame. (7) Dipping in methyl alcohol (A.R.) for 30 minutes. (8) Giesma staining 20 for 24 hours. To be satisfactory, sections should be thin enough to contain one layer of cells only.

2. Bacteriology.-One of the 28 cases could hardly be designated as ophthalmia neonatorum, as the ophthalmia occurred in a boy aged 2 years. The smear and culture in this case showed abundance of staphylococcus aureus. In the remaining 27 cases no organisms were present either in the smear or culture in 24 cases, whilst in one of the residual 3 cases the staphylococci and diphtheroids present were scanty and regarded as of no pathogenic significance.

3. Clinical features.

a. Onset.-The following table shows the day of onset after birth in 27 cases arranged in two groups : 25 cases with inclusion bodies only and the 2 cases showing associated organisms :-

\begin{tabular}{r|c|c}
\hline Onset on & $\begin{array}{c}\text { Inclusion } \\
\text { bodies }\end{array}$ & Inclusion bodies and organisms \\
\hline 2nd day & 1 & - \\
3rd day & 2 & 1 (Koch-Weels) \\
4th day & 1 & - \\
5th day & 1 & - \\
6th day & 3 & - \\
7th day & 4 & - \\
8th day & 3 & 1 (Haemolytic streptococci) \\
9th day & 2 & - \\
10th day & 2 & - \\
11th day & 1 & - \\
12th day & 4 & - \\
20th day & 1 & - \\
\hline
\end{tabular}


It will be seen that of the 25 uncomplicated cases showing inclusion bodies, in 20 the onset occurred on or after the 6 th day of life.

b. Severity.-The condition was bilateral in 16 cases, and unilateral in 11. Discharge was slight in 3 cases, moderate in 18 and profuse in 6 ; muco-pus only was present in 14 cases, the other 13 showing pus. "Marked oedema of the lids was noted 6 times. The corneae were clear in all cases but one, in which they were hazy on admission.

c. Course.-Neither on admission nor during the course of treatment did these $2 \pi$ cases show. any features distinguishing them from other cases of ophthalmia neonatorum.

$d$. Treatment.-One case was treated with penicillin locally and . will be discussed in a subsequent publication on penicillin in ophthalmia neonatorum. The remaining 27 cases received sulphonamides by mouth; 6 showed clinical cure, within 1-3 days; 18 required 4-8 days, and the remaining 3 from 9-30 days. These results- are parallel to those obtained in ophthalmia neonatorum of bacterial origin (Sorsby and Hoffa, 1944). The sulphonamide used was : sulphapyridine in 10 cases, sulphathiazole in 6 , sulphamezathine in 5, sulphadiazine in 3 , and in 2 cases two or more preparations were used. No obvious difference in response to the different sulphenamides could be established in this small series.

4. Genital origin of the affection.-In 25 instances the mothers were admitted with the babies. Gonorrhoea was not present in any of them, and in 5 instances inclusion bodies were found in the scrapings from the cervical epithelium (Figs. 1 and 4), carried out as a special measure in these 25 cases. These 5 cases showed the following features, of interest :

(i) History of leucorrhoea during pregnancy : 3 times. The discharge was slight in 2 mothers and more severe in 1.

(ii) Cervical and urethral smears. Smears: No organisms found, 1 case. Gram positíve cocci, 3 casses. Gram positive Doederlein bac., 1 case.

Cultures: Staphylococci, 1 case; staphylococcus albus, 1 case; staphylococci and diphtheroids, 1 case; diphtheroids only, 1 case; bac. coliform and diphtheroids, 1 case.

(iii) Local condition. Old cervicitis with adhesions was noted in one casé, and slight persistent discharge in 2 more (Miss G. Sands' report).

Technique for cervical scraping to demonstrate inclusion bodies. - Essentially the procedure is the same as for taking scrapings from the conjunctiva with the appropriate modifications of technique. The scraping should be taken from the transitional epithelium at the orifice of the cervix. There is considerable difficulty in getting clean and sufficiently thin scrapings owing to 


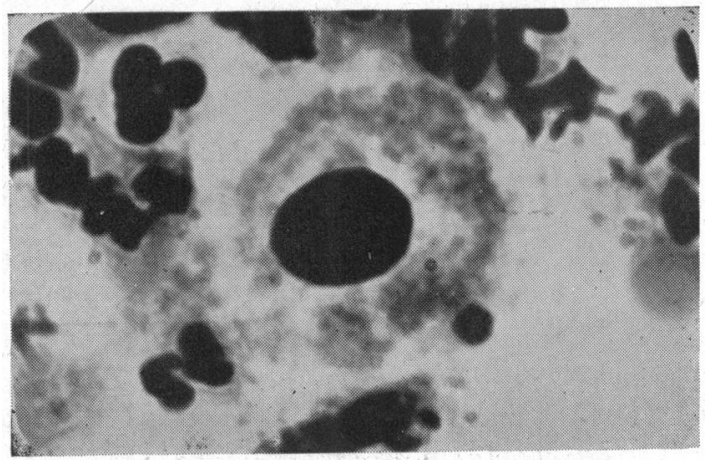

Fig. 1.

Mrs. E. B.-Cervical scraping showing initial body in cytoplasm of epithelial cell.

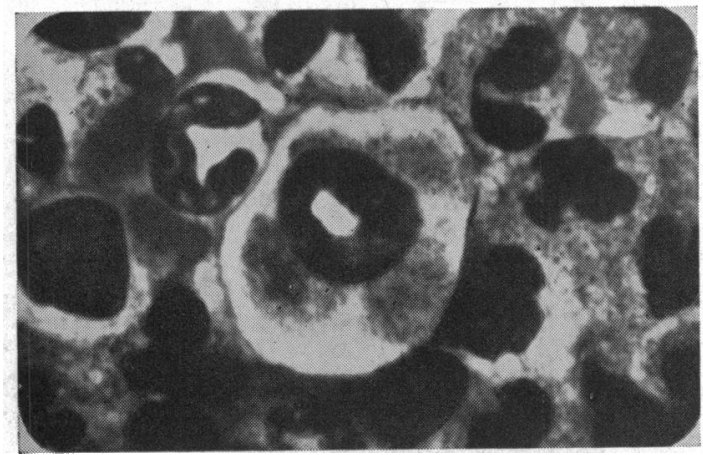

FIG. 2.

Infant B.-Scraping from conjunctiva (of infant of Mrs. E. B) showing elementary bodies.

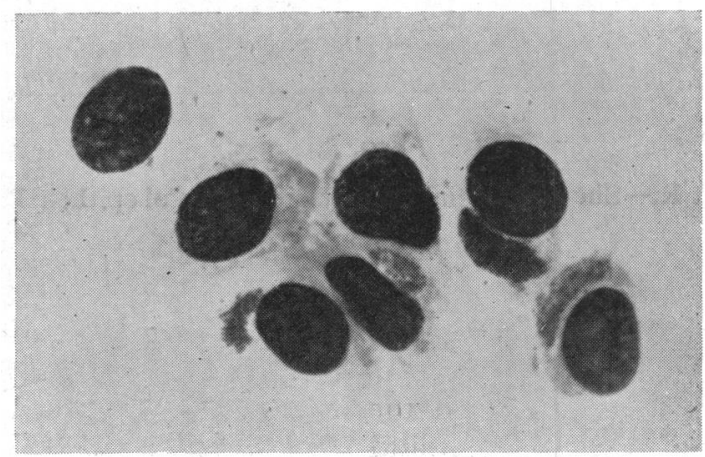

FIG. 3.

Infant K.-Scraping from conjunctiva showing elementary bodies in cytoplasm of epithelial cell. 


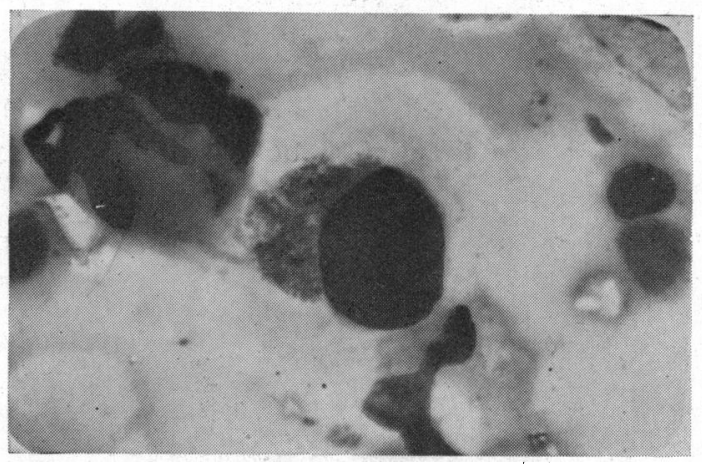

FIG. 4.

Mrs. H.- Cervical scraping showing elementary bodies in cytoplasm of epithelial cell.

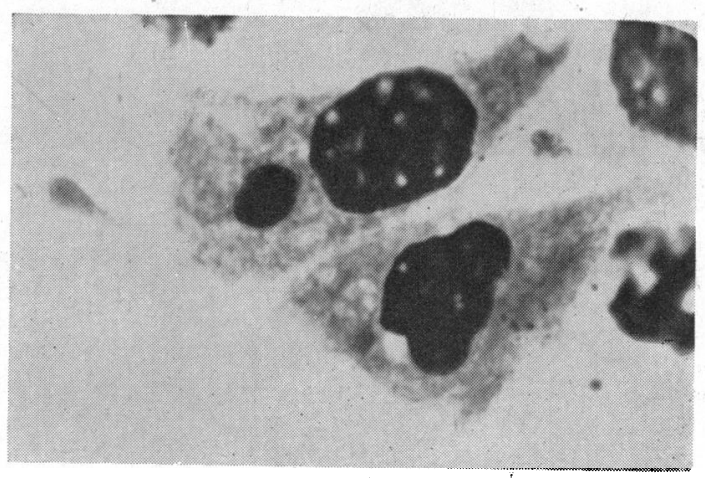

FIG. 5

Infant R.-Showing initial body in cytoplasm of epithelial cell. 
the softness of the cervix in the post-partum period and the tendency to bleeding and discharge.

5. Validity of these-findings.-The presence of inclusion bodies in conjunctival and cervical scrapings does not, of course, establish the virus origin of the ophthalmia in these 27 cases. It has to be proved that these inclusions are pathogenic, and only inoculations in the baboon (or in human volunteers) could establish this. Such inoculations were not carried out and the validity of these findings is assumed on the basis that the inclusions are morphologically of the same type (extra nuclear; cyteplasmic) as that recorded by other observers. In one case the mother's serum was subjected to a complement fixation test with a psittacosis antigen with a negative result (Prof. S. P. Bedson).

\section{Summary}

1. An account is given of the inclusion type of ophthalmia neonatorum.

2 . From a study of 27 cases observed in a series of 269 cansecutive cases of ophthalmia neonatorum at White Oak Hospital it is concluded that, apart from a later onset in most but by no means all cases, inclusion blenorrhoea has no distinguishing features from microbial ophthalmia neonatorum, either in course or in response to sulphonanide therapy.

3 . In 5 out of 25 mothers of infants with inclusion blenorrhoea cervical scrapings showed inclusion bodies.

We are indebted to Dr. G. Heisler, the Matron and Sister Condon of White Oak Hospital for their willing help.

\section{REFERENCES}

The pioneer literature on the significance of inclusion bodies and their bearing on ophthalmia neonatorum is summarised by $L$. A. Julianelle: The Etiology of Trachoma ; New York: The Commonwealth Fund, 19,38, pp. 103-112; and by $P$. Thygeson, Trans. Amer. Ophthal. Soc., Vol. XXXIV, pp. 340-343, 1936. The following references are to recent publications :-

ALI.EN - Quo'ed by Thygeson, 1943.

Aust, O.-Arch.f. Ophthal., Vol. CXXIII, p. 93, 1933

BRALEY, A. E.-Arch: of Ophthat., Vol. XXI, p. 735, 1939; ibid., Vol. XXII, pp. 262 ańd 393,1939 ; ibid. Vol. XXVII, p. 119, 1942.

Amex. Jl. Ophthal., Vol. XXI, p. 1203, 1938.

Flack, J. V̀.-Sight Saving Review, Vol. XII, p. 120, 1942.

GIDDENS and How ARD.-Quoted by Thygeson, 1943.

JAMES, WILliam.-Amer. Jl. Ophthal., Vol. XIII, p. 1084, 1930.

Lugossy, L. J:-Ophthalmologica, Vol: C, p. 68, 1940.

Lumbroso, U.-Arch. Inst. Past. de Tunis, Vol. XXII, p. 513, 1933 ; ibid., Vol. XXIII, p. 60, 1934 .

MCKeE, S. H.-Amer. Jl. Ophthal., Vol. XXV, p. 52, 1942.

SorSBY, A. and HofFA, E.-Brit. Med. Jl., Vol. I, p. 353, 1944

THYGESON, P.-Amer. Jl. Ophthal., Vol. XVII, p. 1019, 1934.

Trans. Amer. Ophthal. Soc., Vol XXXIV: p. 340, 1936

THYGeson, P. and MENGERT, W. F.-Arch. of Ophthal., Vol. XV, p. 377, 1936.

ThYGeson, P. and Stone, W. (a)-Arch. of Ophthal., Vol. XXVII, p. 91, 1942 ; (b) Jl. Amer. Med Assoc., Vol. CXIX, p. 407, 1942.

Thygeson, P.-Arch. of Ophthal., Vol. XXIX, p. 1011, 1943.

VAN Rooyen, C. E. and Rhodes, A. J.-Virus Diseases of Man London : Oxford University Press 1940. 